\title{
2 Zooming in on the Global Hotspots of Rainfed Agriculture in Water-constrained Environments
}

\author{
J. Rockström* and L. Karlberg \\ Stockholm Environment Institute (SEI), Stockholm, Sweden; \\ email:*johan.rockstrom@sei.se
}

\section{Introduction}

Rainfed agriculture is practised on $80 \%$ of the world's agricultural area and generates $60-70 \%$ of the world's staple food ${ }^{1}$ (FAOSTAT, 2005). In semi-arid and dry subhumid zones, rainfed agriculture dominates food production systems, and water is a key limiting factor to crop growth (SEI, 2005). Since approximately $70 \%$ of the world's poor are women, the importance of rainfed sources of food weighs disproportionately on women (WHO, 2000). Agriculture plays a key role for economic development (World Bank, 2005), poverty reduction (Irz and Roe, 2000) and economic growth (van Koppen et al., 2005). Every $1 \%$ increase in agricultural yield translates to a $0.6-1.2 \%$ decrease in the percentage of absolute poor ${ }^{2}$ (Thirtle et al., 2002). In sub-Saharan Africa for example, agriculture accounts for $35 \%$ of the gross domestic product (GDP) and employs $70 \%$ of the population (World Bank, 2000), and more than $95 \%$ of the agricultural area is rainfed (FAOSTAT, 2005). Thus, in this region, agriculture is the engine of overall economic growth and, therefore, broad-based poverty reduction (Johnston and Mellor, 1961; World Bank, 1982; Timmer, 1988; Abdulai and Hazell, 1995; IFAD, 2001; DFID, 2002; Koning, 2002).
There are thus strong reasons to believe that in many areas poverty is strongly influenced by agricultural production, which in turn is dependent on climate in general and water availability in particular. Despite the complex driving forces behind poverty, the social-ecological interactions between livelihoods, agriculture and water constraints make it important to analyse the degree of interdependence and the regions of the world where these factors interact. Identifying such regions can provide an important guide for new investments in upgrading rainfed agriculture.

The aim of this chapter is to identify global hotspots of rainfed agriculture where water constitutes a key limiting factor to crop growth. Thus, the focus is on the dry subhumid, semiarid and arid zones. First, we investigate the link between climate and poverty. Thereafter, the number of people living in water-constrained agricultural areas is estimated. Based on this analysis, the global hotspots for rainfed agricultural areas in water-constrained environments are identified.

\section{Most Poor Live in Water-constrained Environments}

There is a correlation between poverty and water stress (Falkenmark, 1986). The UN Millennium 
Development Project has identified the hotspot countries in the world suffering from the largest prevalence of malnourishment. These countries coincide closely with those located in the semi-arid and dry subhumid hydroclimates of the world (Fig. 2.1), i.e. savannah and steppe ecosystems. Of the 850 million undernourished people in the world, essentially all live in poor developing countries, which predominantly are located in tropical and subtropical regions (UNSTAT, 2005).

\section{A Fifth of the World's Population Lives in Water-constrained Agricultural Areas}

To make a quantitative assessment of the number of people depending on rainfed and irrigated agriculture for their livelihoods in different hydroclimatic zones, geographically distributed data was analysed. An overview of the data sets is given in Table 2.1. All data sets were re-sampled to a resolution of $2.5 \mathrm{~min}$ and continuous variables were reclassified into discrete classes, except for population.

Data on land use were derived from the Global Land Cover data set (GLC2000, 2003), in which the class "cultivated and managed areas'3 was chosen to represent the total agricultural area. Second, a data set produced by the FAO (Food and Agriculture Organization, the United Nations) was used to represent irrigated agricultural land use (Siebert et al., 2005). This data set shows the percentage of the agricultural area equipped for irrigation. We

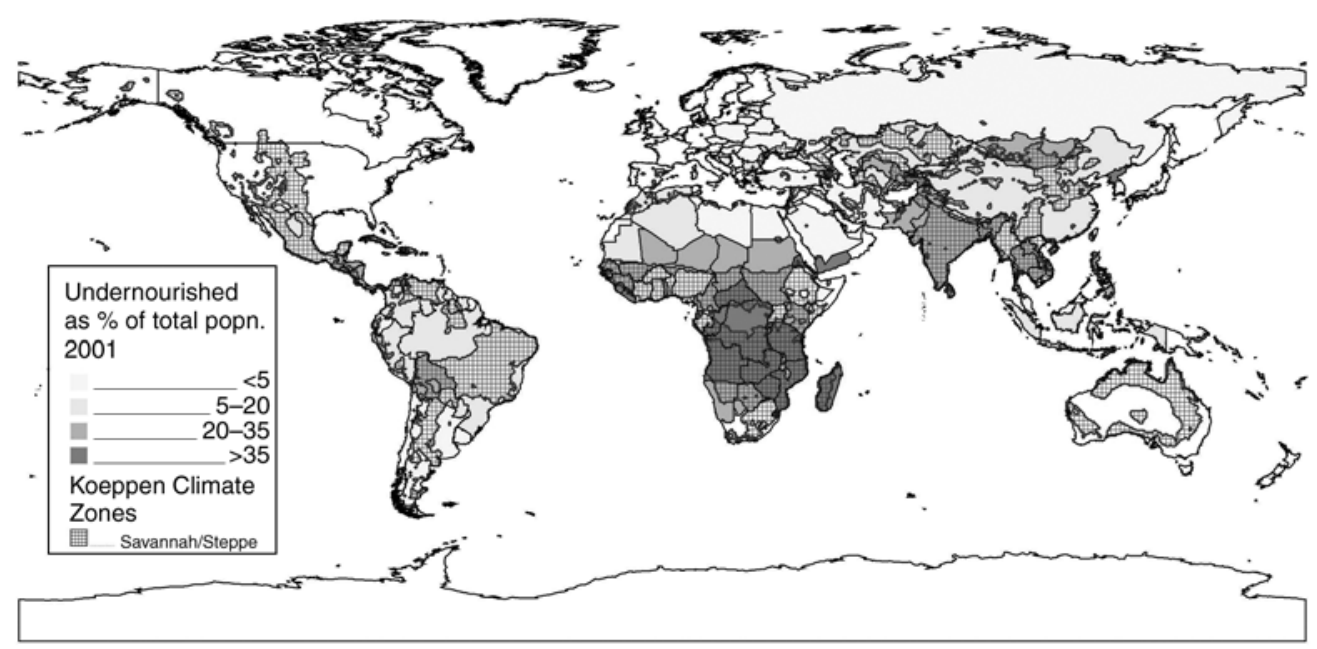

Fig. 2.1. The prevalence of undernourishment in developing countries (as percentage of population 2001/2002; UNSTAT, 2005), together with the distribution of semi-arid and dry subhumid hydroclimates in the world, i.e, savannah and steppe agroecosystems. These regions are dominated by sedentary farming subject to the world's highest rainfall variability and occurrence of dry spells and droughts.

Table 2.1. Datasets used in the analysis of hydroclimate, poverty and land use.

\begin{tabular}{|c|c|c|c|c|}
\hline Dataset & Source (see text) & Resolution & Continuous data & Classes \\
\hline \multicolumn{5}{|l|}{ Land use } \\
\hline $\begin{array}{l}\text { Agricultural land } \\
\text { Irrigated land }\end{array}$ & $\begin{array}{l}\text { GLC2000 FAO } \\
\text { (Siebert et al., 2005) }\end{array}$ & $\begin{array}{r}0.5 \min \\
5 \mathrm{~min}\end{array}$ & $N A^{a}$ & $\begin{array}{l}\text { Irrigated agriculture } \\
\text { Rainfed } \\
\text { agriculture/other }\end{array}$ \\
\hline Hydroclimate & $\begin{array}{l}\text { FAO based on CRU } \\
\text { CL } 2.0\end{array}$ & $5 \mathrm{~min}$ & Aridity index & $\begin{array}{l}\text { Arid/semi-arid/dry } \\
\text { subhumid/humid }\end{array}$ \\
\hline Population & GPWv3 & $2.5 \mathrm{~min}$ & Number of people & $N A^{a}$ \\
\hline
\end{tabular}

a $\mathrm{NA}=$ data not available. 
classified areas with more than $30 \%$ of the fields equipped for irrigation as 'irrigated agriculture', which corresponds to about $20 \%$ of the total agricultural area and is thus in accordance with the estimates by the FAO (FAOSTAT, 2003). Rainfed agricultural area was determined by subtracting irrigated agricultural area from the total agricultural area. This means that in pixels classified as irrigated, there might be rainfed fields as well, and vice versa. The classification is thus independent of rainfall amounts.

Water constraints are here defined only in terms of hydroclimate and described by an aridity index (AI) ${ }^{4}$ provided by the FAO (2006). They created the AI data from climatic variables in the data set CRU CL 2.0 (New et al., 2002), and by calculating reference potential evapotranspiration according to the Penman-Monteith equation as described by Allen et al. (1998). Because $\mathrm{Al}$ was given as a continuous variable in the data set, it had to be reclassified into four hydroclimatic zones: arid ( $\mathrm{AI}<0.20)$, semi-arid (AI 0.20 to $<0.50$ ), dry subhumid (AI 0.50 to $<0.65$ ) and humid (AI > 0.65). A global population data set, Gridded Population of the World (GPWv3), produced by SEDAC (SocioEconomic Data and Applications Centre), was used in the analysis (CIESIN and CIAT, 2005). A methodological documentation of the GPWv3 is given in Balk and Yetman (2004).

The analysis shows that approximately $50 \%$ of the total global land area is located in waterconstrained regions (Table 2.2), which is slightly higher in comparison with other studies (e.g. Safriel and Adeel, 2005). In particular, the esti- mate of the arid zone area deviates from the literature value. About $36 \%$ of the global population live in areas subject to water constraints, a figure which is in agreement with other estimates (Safriel and Adeel, 2005). Thus, it seems that the differences in area estimation of the arid regions make little difference in terms of population, probably owing to low population density in arid regions.

Agricultural area is about $13 \%$ of the total land area, which corresponds well with data found in FAOSTAT (2003; data for arable land and permanent crops). Although this area is rather small, almost half of the global population $(47 \%)$ lives in agricultural areas. This is slightly higher than the estimation by FAO from the year 2000 of $42 \%$ (FAOSTAT, 2000).

These data sets were then used to calculate the number of people living in agricultural areas in the different hydroclimatic zones. The results show that about 1.11 billion people, corresponding to $17 \%$ of the total global population, lives from agriculture in waterconstrained environments (Fig. 2.2). Out of that, almost half $(8.2 \%$ of the world population) lives in rainfed agricultural areas, while the other half $(8.9 \%$ of the world population) lives in irrigated agricultural areas. In the arid zone, more people live in irrigated agricultural areas compared with rainfed agricultural areas, which is to be expected since irrigation is needed to secure crop yields. On the other hand, in slightly wetter areas (i.e. semi-arid and dry subhumid), more people live in rainfed agricultural areas compared with irrigated agricultural areas.

Table 2.2. Area of land population in different hydroclimatic zones and land use areas from GIS analysis.

\begin{tabular}{lcc}
\hline Region & Area (\% of total land area) & Population $(\%$ of total) \\
\hline Hydroclimate & & $7.2(5.8)^{\mathrm{b}}$ \\
Arid (including hyperarid) & $23(17)^{\mathrm{b}}$ & $16(14)^{\mathrm{b}}$ \\
Semi-arid & $18(15)^{\mathrm{b}}$ & $13(15)^{\mathrm{b}}$ \\
Dry subhumid & $9(9)^{\mathrm{b}}$ & $36(36)^{\mathrm{b}}$ \\
Total & $50(41)^{\mathrm{b}}$ & \\
Land use & $11(9.7)^{\mathrm{c}}$ & 28 \\
Rainfed agriculture & $2.1(2.1)^{\mathrm{c}}$ & 19 \\
Irrigated agriculture & $13(12)^{\mathrm{c}}$ & $47(42)^{\mathrm{d}}$ \\
Total &
\end{tabular}

a Figures in parenthesis are literature values; ${ }^{b}$ Safriel and Adeel (2005); ${ }^{c}$ FAOSTAT (2003); ${ }^{d}$ FAOSTAT (2000). 


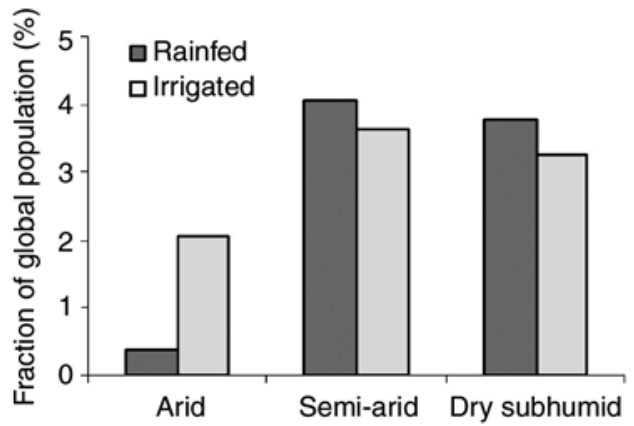

Fig. 2.2. Number of people in each hydroclimatic and land use zone in relation to the total global population.

\section{Zooming in on the Hotspots for Water-constrained, Rainfed Agriculture}

Three regions were identified as hotspots for water-constrained, rainfed agriculture, namely Africa, South Asia and East Asia (Fig. 2.3). Each of these regions hosts more than 100 million poor people depending on rainfed agriculture in water-constrained environments. Taken together, the total number of people in these three areas constitutes about $80 \%$ of all people living in water-constrained, rainfed agricultural areas, corresponding to 426 million people. In Africa, most of these people live in a band stretching from Senegal, through Mali, Burkina Faso, Niger, Nigeria, Chad, Sudan, Ethiopia, Kenya, Tanzania, Zambia, Malawi, Mozambique, Zimbabwe and ending in South Africa. This area constitutes a large share of the total agricultural area in Africa, and in this region the prevalence of undernourishment is high (Fig. 2.1). The majority of the population living in water-constrained, rainfed agricultural areas in South Asia live in western India, and also partly in Pakistan and Afghanistan. Despite the fact that large parts of eastern India are agricultural land, this part of the country is substantially wetter, which explains the lack of people living in water-stressed conditions in that area. Lastly, in East Asia, the vast majority of the people living in water-constrained, rainfed agricultural areas are found on the north-eastern and north China plains. Although agricultural land extends further south in the country, it is only these two regions that are water constrained.
There is a clear difference between the three regions in terms of population density within the selected environment (Fig. 2.3); in Africa the population density is only about 0.5 persons per hectare, while it is more than four times greater in South Asia. Moreover, there is a difference between the three regions in terms of hydroclimate (Fig. 2.3). In comparison with the other regions, a relatively large part of the area is semi-arid in Africa, dry subhumid in East Asia, and arid in South Asia; however, in all three regions the semi-arid area dominates over the others, while the arid area is the smallest. Farming systems are similar in the three regions, with sedentary farming dominating in the semiarid and dry subhumid regions, and with agropastoral systems in the transitional zone between dry semi-arid and semi-arid regions, particularly in Africa and East Asia. All three regions are dominated by small-scale rainfed farming, with a higher degree of mechanization in South and East Asia, as compared with Africa. Africa is the only region still practising (though limited) shifting cultivation.

Characteristic for Africa, South Asia and East Asia is that yields generally are lower than the world average ${ }^{5}$, with a few exceptions (Fig. 2.4a). This can be viewed as an opportunity for improvements in the form of investments into water management in these regions, given the large opportunities for improved agricultural and water productivity even in waterconstrained regions. Moreover, GDP is very low in both Africa and South Asia, in comparison with the world average, and also a little bit below the world average in East Asia (Fig. $2.4 \mathrm{~b})$. Poverty is thus generally prevalent in these regions, which hampers investments in agricultural inputs such as water management techniques and nutrients. The large number of people who depend on rainfed agriculture in water-constrained environments, the low yields and the high incidence of poverty in these regions can also be interpreted as a cause and effect relationship between water availability, crop production and poverty. In other words, where water limits crop production, poverty is strongly linked to variations in rainfall and to the farmers' ability to bridge intraseasonal dry spells. Livelihoods depend strongly on water availability, a relationship that is well established for economies highly dependent on the 


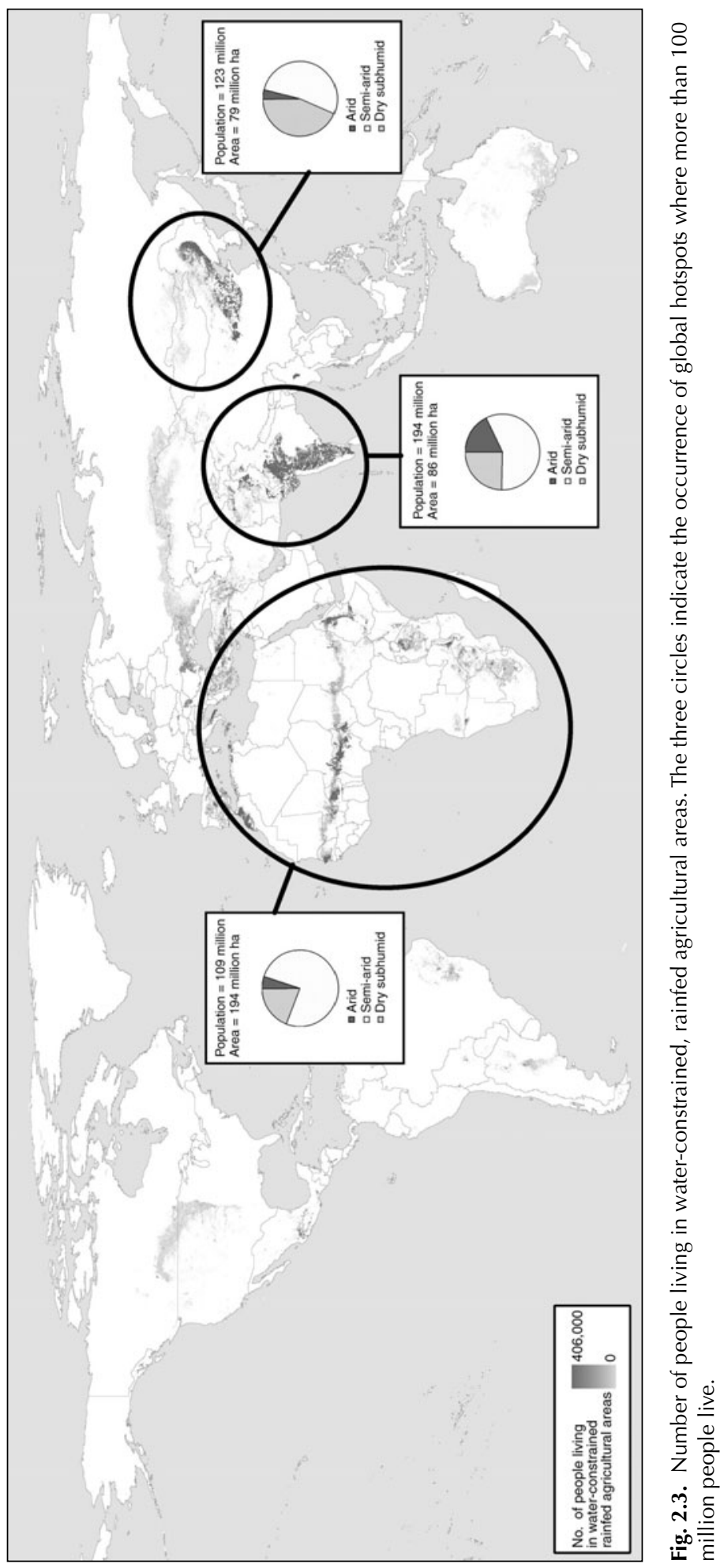



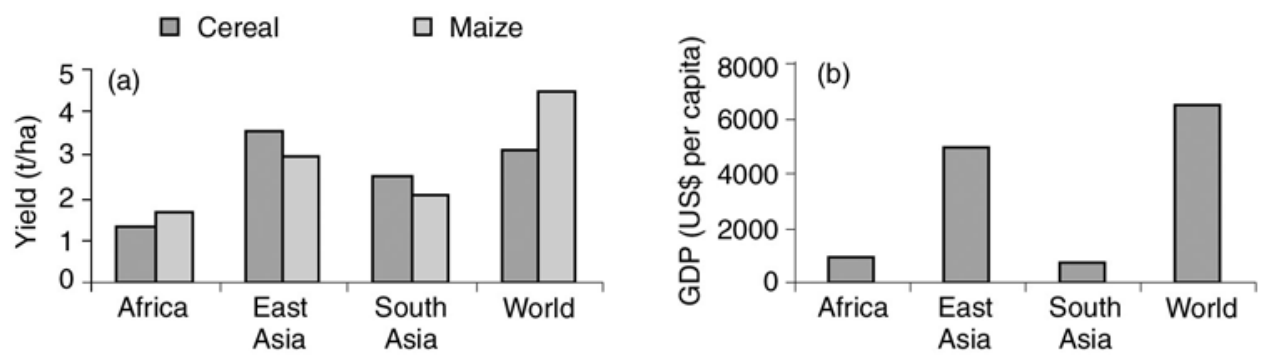

Fig. 2.4. Comparison between (a) average yields (FAOSTAT, 2003) and (b) gross domestic product (GDP) (UNSTAT, 2004) for the three global hotspot regions for water-constrained, rainfed agriculture. Cereals include barley, maize, millet, oats, rice, rye, sorghum and wheat. GDP for South Asia also includes data for Central Asia.

agrarian sector, resulting, for example, in a close correlation between average annual rainfall and GDP growth (Brown and Lall, 2006).

\section{Linking Poverty, Land Use and Hydroclimate}

Assessments of the relationships between poverty, hydroclimate and land use have previously not been conducted at a sub-national level, and therefore estimates on the number of poor that depend on rainfed agriculture as their main source of income, in areas where water poses constraints on agriculture, are still lacking. This chapter provides an identification of the global hotspots for combined water stress and rainfed agricultural land use. Moreover, the relationship between poverty and hydroclimate is discussed. The next step would be to quantitatively estimate the number of poor living off rainfed agriculture in water-constrained environments; however, such an analysis requires reliable global poverty data at a high resolution.

\section{Conclusions}

Poverty generally seems to be relatively prevalent in water-constrained areas. This could be due to the fact that many poor people's livelihoods depend on crop production from rainfed agriculture in water-constrained environments. It is estimated that about 1.11 billion people, corresponding to $17 \%$ of the total global population, live in agricultural areas in water-constrained environments, and out of that $8.2 \%$ of the population, lives specifically in rainfed agricultural areas. In Africa, East Asia and South Asia more than one million people in each region live in rainfed agricultural areas where water poses a key constraint for crop production. These regions are characterized by low crop yields and GDP levels. Again, this could be interpreted as an effect of water constraints on crop production, which in turn could affect poverty in regions where many people derive their livelihoods from rainfed agriculture. The conclusion would thus be that investments in water management to upgrade rainfed agriculture in these hotspot regions are likely to have a large impact on poverty reduction. Moreover, the Millennium Development Goals on hunger and poverty require increased focus on water management in rainfed agriculture.

\section{Acknowledgements}

We are very grateful to Duncan McConnachie, who provided invaluable help with the GISanalysis. Jippe Hoogeveen, FAO, kindly shared the hydroclimate data set with us.

\section{Notes}

1 Food that forms the basis of a traditional diet, and thus varies from place to place. Typically inexpensive starchy foods of vegetable origin, e.g. cereals that are high in calories and carbohydrate and that can be stored for use throughout the year. 
2 Poverty is generally understood as the condition of having little money and few material possessions. Factors that are part of poverty include: precarious livelihoods, excluded locations, physical limitations, gender relationships, social relationships, lack of security, abuse by those in power, limited capacities, disempowering institutions and weak community organizations. The term 'absolute poor' used in the chapter refers to poverty in relation to an absolute poverty threshold. In this chapter the term 'poor' refers to those 850 million people that are undernourished according to UNSTAT (2005).

3 This class includes herbaceous, shrub and tree crops (irrigated and rainfed), as well as flooded crops.

4 Precipitation divided by potential evapotranspiration.

${ }^{5}$ In the African hotspot, the main crops are maize, millet and sorghum, in South Asia it is millet and wheat and in the China hotspot it is wheat, maize and soybean.

\section{References}

Abdulai, A. and Hazell, P. (1995) The role of agriculture in sustainable development in Africa. Journal of Sustainable Agriculture 7(2/3), 101-119.

Allen, R.G., Pereira, L.S., Raes, D. and Smith, M. (1998) Crop evapotranspiration - guidelines for computing crop water requirements. FAO Irrigation and Drainage. Paper 56. Food and Agriculture Organization of the United Nations (FAO), Rome, Italy.

Balk, D. and Yetman, G. (2004) The Global Distribution of Population: Evaluating the Gains in Resolution Refinement. Center for International Earth Science Information Network (CIESIN), Columbia University, USA.

Brown, C. and Lall, U. (2006) Climate and development: the role of variability and a framework for resilience. Natural Resources Forum 30, 4.

CIESIN (Center for International Earth Science Information Network) and CIAT (Centro Internacional de Agricultura Tropical) (2005) Gridded Population of the World Version 3 (GPWv3): Population Grids. Socioeconomic Data and Applications Center (SEDAC), Columbia University, USA. (Available at http://sedac.ciesin.columbia.edu/gpw).

DFID (Department for International Development) (2002) Better livelihoods for poor people: the role of agriculture. Issues Paper. DFID Rural Livelihoods Department, London, UK (Consultation Document Draft A4).

Falkenmark, M. (1986) Fresh water - time for a modified approach. Ambio 15(4), 192-200.

FAO (2006) Aridity-index global data set. 5 min resolution. Provided by Jippe Hoogeveen. Food and Agriculture Organization of the United Nations (FAO), Rome, Italy.

FAOSTAT (2000) http://faostat.fao.org/ (last accessed November 2005).

FAOSTAT (2003) http://faostat.fao.org/ (last accessed November 2005).

FAOSTAT (2005) http://faostat.fao.org/ (last accessed November 2005).

GLC2000 (The Global Land Cover Map for the Year 2000) (2003) GLC2000 database. European Commission Joint Research Centre (http://www-gem.jrc.it/glc2000).

IFAD (2001) Rural Poverty Report 2001: the Challenge of Ending Rural Poverty. International Fund for Agricultural Development (IFAD), Oxford, UK.

Irz, X. and Roe, T. (2000) Can the world feed itself? Some insights from growth theory. Agrekon 39(3), 513-528.

Johnston, D.G. and Mellor, J.W. (1961) The role of agriculture in economic development. American Economic Review 51(4), 566-593.

Koning, N. (2002) Should Africa protect its farmers to revitalise its economy? Working Paper North-South Centre. Wageningen University and Research Centre, Wageningen, the Netherlands.

New, M., Lister, D., Hulme, M. and Makin, I. (2002) A high-resolution data set of surface climate over global land areas. Climate Research 21, 1-25.

Safriel, U. and Adeel, Z. (2005) Dryland systems. In: Hassan, R., Scholes, R. and Ash, N. (eds) Ecosystems and Human Well-being, Current State and Trends, Vol. 1. Millennium Ecosystem Assessment, Island Press, Washington, USA, pp. 623-662.

SEI (2005) Sustainable pathways to attain the Millennium Development Goals - assessing the role of water, energy and sanitation. Document prepared for the UN World Summit, 14 September 2005, New York, USA. Stockholm Environment Institute, Stockholm, Sweden (http:// www.sei.se/mdg.htm).

Siebert, S., Döll, P., Feick, S. and Hoogeveen, J. (2005) Global Map of Irrigated Areas Version 3.0. Johann Wolfgang Goethe University, Frankfurt am Main, Germany; and Food and Agriculture Organization of 
the United Nations, Rome, Italy (http://www.fao.org/geonetwork/srv/en/main.home; last accessed November 2006).

Thirtle, C., Beyers, L., Lin, L., Mckenzie-Hill, V., Irz, X., Wiggins, S. and Piesse, J. (2002) The impacts of changes in agricultural productivity on the incidence of poverty in developing countries. DFID Report No. 7946. Department for International Development (DFID), London, UK.

Timmer, C.P. (1988) The agricultural transformation. In: Chenery, H. and Srinivasan, T.N. (eds) Handbook of Development Economics, Vol. 1. North-Holland, Amsterdam, the Netherlands, pp. 113-135.

UNSTAT (2004) www.unstat.com (last accessed in 2004).

UNSTAT (2005) www.unstat.com (last accessed in 2005).

van Koppen, B., Namara, R. and Stafilios-Rothschild, C. (2005) Reducing poverty through investments in agricultural water management. Poverty and gender issues and synthesis of sub-Saharan Africa case study reports. Working Paper 101. International Water Management Institute (IWMI), Colombo, Sri Lanka.

WHO (2000) Gender, health and poverty. Factsheet No. 25. June (http://www.who.int/mediacenter/ factsheets/fs251/en/).

World Bank (1982) World Development Report 1982. Oxford University Press, New York, USA.

World Bank (2000) Spurring agricultural and rural development. In: Can Africa Claim the 21st Century? The World Bank, Washington, DC, USA, pp. 170-207.

World Bank (2005) Agricultural Growth for the Poor: an Agenda for Development. The International Bank for Reconstruction and Development/The World Bank, Washington, DC, pp.1-19. 